\title{
Statin therapy Prescribing patterns for primary prevention of Cardiovascular disease in patients with type 2 Diabetes Mellitus receiving primary care at the Tamale Teaching Hospital (TTH) in Northern Ghana
}

\author{
Martin Mumuni Danaah Malick ${ }^{1,2}$, Stephen Adjei ${ }^{3}$ \\ ${ }^{1}$ Tamale Teaching Hospital, Department of Pharmacy; \\ ${ }^{2}$ University for Development Studies, Department of Pharmacy; \\ ${ }^{3}$ Tamale Teaching Hospital, Department of Pharmacy.
}

*Corresponding author: Martin Mumuni Danaah Malick, Tamale Teaching Hospital, Department of Pharmacy

Received date: July 10, 2020; Accepted date: July 03, 2020; Published date: July 10, 2020

Citation: Danaah Malick MM., Adjei S., (2020) Statin therapy Prescribing patterns for primary prevention of Cardiovascular disease in patients with type 2 Diabetes Mellitus receiving primary care at the Tamale Teaching Hospital (TTH) in Northern Ghana. J, Clinical Cardiology and Cardiovascular Interventions, 3(7); Doi:10.31579/2641-0419/070

Copyright: (C) 2020 Martin Mumuni Danaah Malick, This is an open access article distributed under the Creative Commons Attribution License, which permits unrestricted use, distribution, and reproduction in any medium, provided the original work is properly cited.

Abstract
Background: One of the leading causes of morbidity and mortality amongst type 2 diabetic (T2DM) patients
is Cardiovascular disease (CVD). Patients with T2DM are at a higher risk of developing CVD than non-diabetic
patients. Statin therapy has been proven to be effective for the primary prevention of CVD amongst T2DM
patients. The objective of this study was to determine the extent of statin therapy use for primary prevention of
CVD in T2DM patients at TTH.
Methods: A retrospective review of prescription records of T2DM patients who attended the Diabetes Clinic
between January 12019 to March 312019 was conducted. Patient-specific data, evidence of T2DM Diagnosis
and prescribed statin therapy were retrieved. Data was collected using a pre-structured tool and analyzed with
STATA 15.0.
Results: A total of 171 patients were included in this study. Of these, only 49\% (84) patients received a statin.
Atorvastatin 20mg was prescribed for 76\% (64) patients, followed by atorvastatin 10mg for 22\% (19) patients.
Atorvastatin 40 mg and simvastatin 20 mg was the least prescribed at $1 \%$ (1) patient each. A total of $76 \%$ of
statin therapies were of moderate-intensity dose, 23\% were of low-intensity dose and only $1 \%$ was of high-
intensity dose.
Conclusion: Despite the overwhelming evidence supporting the cardiovascular benefits of statins in T2DM
patients, these therapeutic agents are under-prescribed for T2DM patients at TTH with atorvastatin being the
most frequently prescribed statin therapy.
Keywords: pleiotropic properties; statin therapy; primary prevention; CVD; T2DM

\section{Introduction}

Diabetes is a chronic condition caused by a total lack of insulin or decreased insulin because of impaired insulin secretion and action. It is characterized by symptomatic glucose intolerance resulting in hyperglycemia and alterations in lipid and protein metabolism [1]. Diabetes is a global public health concern as it has been recognized as an important cause of premature death and disability with more than 400 million people living with the disease [2]. Long term complications that may arise from diabetes mellitus include cardiovascular disease (CVD), retinopathy, nephropathy, and neuropathy, and a higher risk of cancer [3]. Type 2 diabetes predisposes patients to an increased prevalence of lipid abnormalities which contributes to their high risk of developing ASCVD [4]. Studies indicate that in T2DM, there is a three-to-fourfold elevated risk for myocardial infarction (MI) and cardiovascular death compared to non-diabetic people [5]. Diabetic dyslipidemia is characterized by hypertriglyceridemia, low high-density lipoprotein (HDL) and LDL that is minimally elevated. Patients with type 2 diabetes are at risk of increased cardiovascular morbidity and mortality. This arises from the high prevalence of cardiovascular risk factors such as hypertension, dyslipidemia, obesity, poor glycemic control and albuminuria than nondiabetic patients [6]. Adequate control of these modifiable risk factors helps to reduce the frequency and outcomes of such cardiovascular events in patients.

Studies have shown that controlling these cardiovascular risk factors helps in preventing and slowing cardiovascular events in diabetes [7]. Management of cardiovascular risks in type 2 diabetics is usually grouped into two categories: primary prevention and secondary prevention. Primary prevention refers to those patients without documented atherosclerotic cardiovascular disease (ASCVD) whilst secondary prevention refers to those with documented ASCVD [8]. Statins inhibit the enzyme 3-hydroxy-3-methyl-glutaryl coenzyme A reductase, which is the rate-limiting step in cholesterol synthesis in the body. Statins reduce 
levels of both total cholesterol and low-density cholesterol and to an appreciable extent, the triglycerides [9]. The beneficial cardiovascular effects of statins are associated with their pleiotropic properties [10]. These pleiotropic properties include: improvement of endothelial dysfunction, increased nitric oxide availability, antioxidant properties, inhibition of inflammatory responses, stabilization of plaques, reduction of vascular cell adhesion molecules, stimulation of endothelial progenitor cell recruitment and immunomodulation [11].

Pleiotropic effects of a drug are described as those effects that are completely different from those for which the drug was specifically designed. These unique properties may be related or unrelated to the mode of action of the drug and are usually not readily predictable [12]. These effects act in concert with LDL-cholesterol reduction to provide the overall cardioprotective effects of statin. A thorough understanding of the pleiotropic effects of statins will greatly help practicing clinicians to optimize their use in the treatment and prevention of cardiovascular disease, especially those with concomitant diabetes mellitus [13]. T2DM patients also have elevated CVD risks prompting the need for primary prevention in such patients [14].

The focus of primary prevention is aimed at reducing or delaying the onset of cardiovascular events and improve quality of life. The incidence of CVD related deaths is on the increase in many developed countries and it is currently the leading cause of death globally [15]. Blacks (including Ghanaians) are at higher risk of developing coronary heart diseases (CHD) than other ethnic groups [16].

There are two main statin dosing intensities that are recommended in clinical practice [17]. These are the high-intensity statin therapy and moderate-intensity statin therapy. A low - intensity statin therapy is generally not recommended in patients with T2DM but in some cases, it may be the only dose the patient can tolerate. The high-intensity statin therapy achieves about 50\% reduction in LDL cholesterol while the moderate-intensity therapy achieves between $30-50 \%$ reductions in LDL cholesterol [18].

Recommendations for use of statins in patients with diabetes with atherosclerosis regardless of their age are high-intensity statin therapy complemented with lifestyle modifications. For patients less than 40 years with additional ASCVD factors, moderate-intensity therapy is considered whilst lifestyle modifications are recommended for those who do not have ASCVD factors (19). However, for the primary prevention of cardiovascular events in Type 2 diabetes patients, moderate-intensity statin therapy is initiated in patients between the ages of 40 to 75 years and above 75 years without additional cardiovascular disease risk factors [20].

Underutilization of statins in patients who are at risk for CVDs such as type 2 diabetic patients aged over 40 years has been reported in many forms such as inappropriate dosing, issues with adherence, and discontinuation of medication therapy [21]. It is really difficult to apply entirely the recommendation of clinical Practice guidelines on statins in diabetes in real-world practice [22]. The main objective of this study is to determine the extent of statins used for primary prevention of cardiovascular diseases in Type 2 Diabetes at Tamale Teaching Hospital.

\section{Materials and Methods}

This was a retrospective study conducted at the outpatient diabetic clinic of the TTH between January 1st, 2019 to March 31st, 2019. The Tamale Teaching Hospital is an 800-bed capacity teaching hospital located in the Northern Region of Ghana. It has over 1000 registered diabetic patients who attend the clinic on a biweekly basis and attends to an average of 300 diabetic patients in a month with the majority of them been sponsored by the National Health Insurance Scheme. A purposive sampling technique was used in this study. A data collection tool was structured to enable all relevant data to be obtained from the needed patient records. Data was recorded for one visit during the data collection period. Any follow up visit was not recorded as additional data. Secondary data were obtained from patient records at the Out-Patient Department of TTH. Quantitative data derived from the review of the patients' records were entered into excel and exported to STATA version 15 for statistical analysis. Descriptive analysis (pie charts, frequency tables etc.) was used to summarize and present data on socio-demographic findings of participants. The analysis consisted of the use of the chi-square test to determine the association between the dependent and independent variables and the strength of associations will be affirmed using logistic regression analysis. The level of significance for the chi-square test was accepted where the $p$-value was $p<0.05$ at $95 \%$ confidence level. Permission was obtained from the management of the Tamale Teaching Hospital to allow the principal researcher to collect secondary data.

\section{Exclusion and Inclusion criteria}

All T2DM patients between 40 to 75 years, with no documented diagnosis of cardiovascular diseases, were included in the study. All T2DM patients below the age of 40 years and or with a documented diagnosis of cardiovascular diseases were all excluded from this study.

\section{Results}

Several factors have been ascribed to affect adherence to prescription and use of statins as recommended by guidelines. These include the knowledge of base of the clinicians and familiarity of the newer clinical practice guidelines on statins use primary prevention, a specialty of the prescriber, underestimation of patient's risk by physicians, presence of guidelines disagreement, practice setting limit (Figure. 1) [23]. 


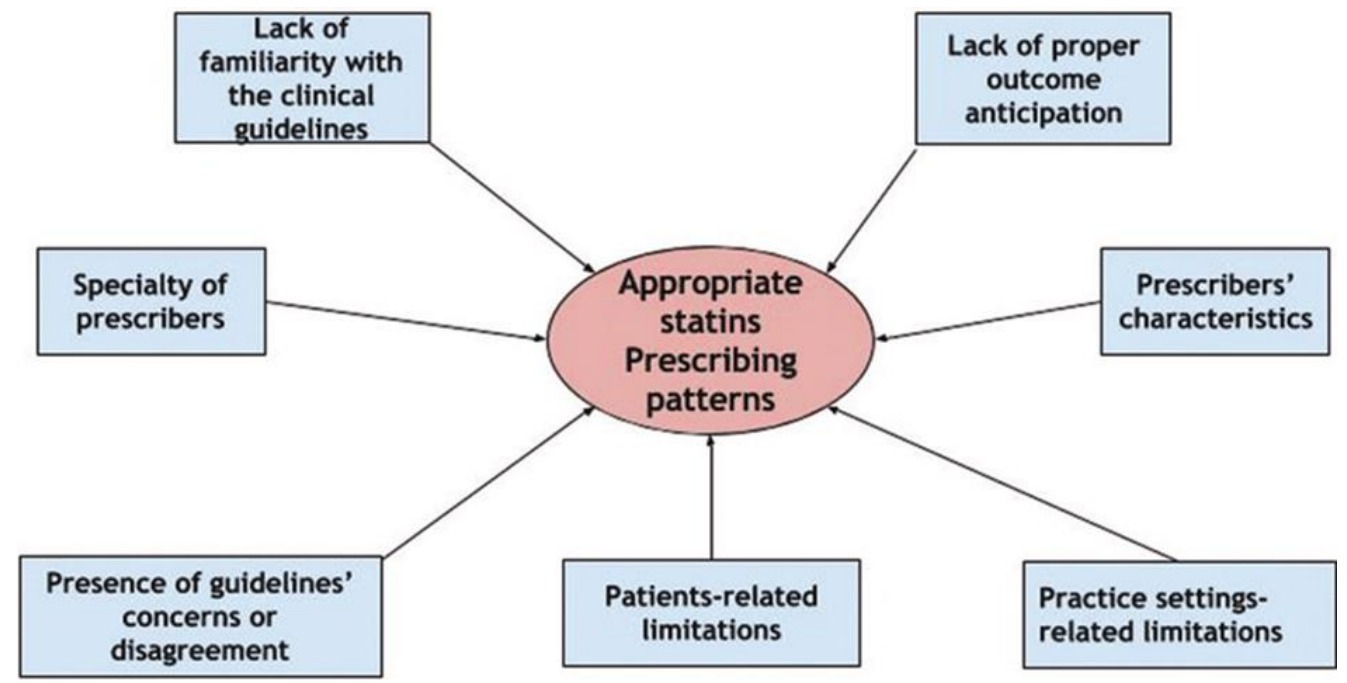

Figure 1: Factors associated with the barriers and challenges to the use of statins in primary care [23,29]

\begin{tabular}{|c|c|c|c|}
\hline \multirow{2}{*}{ Statin } & High-Intensity & Moderate-Intensity & Low-Intensity \\
\hline & Lowers LDL > $50 \%$ & $\begin{array}{l}\text { Lowers LDL } \\
30 \% \text { to } 49 \%\end{array}$ & Lowers LDL <30\% \\
\hline Atorvastatin & $40 \mathrm{mg}-80 \mathrm{mg}$ & $10 \mathrm{mg}-20 \mathrm{mg}$ & \\
\hline Rosuvastatin & $20 \mathrm{mg}-40 \mathrm{mg}$ & $5 \mathrm{mg}-10 \mathrm{mg}$ & \\
\hline Lovastatin & & $40 \mathrm{mg}$ & $20 \mathrm{mg}$ \\
\hline Simvastatin & & $20 \mathrm{mg}-40 \mathrm{mg}$ & $10 \mathrm{mg}$ \\
\hline Pravastatin & & $40 \mathrm{mg}-80 \mathrm{mg}$ & $10 \mathrm{mg}-20 \mathrm{mg}$ \\
\hline Fluvastatin (XL) & & $80 \mathrm{mg}$ & \\
\hline Fluvastatin & & 40 mg (twice daily) & $20 \mathrm{mg}-40 \mathrm{mg}$ \\
\hline Pitavastatin & & $2 \mathrm{mg}-4 \mathrm{mg}$ & $1 \mathrm{mg}$ \\
\hline
\end{tabular}

Table 1: Classification of statin therapies adopted with permission from the authors of the 2013 AHA Guidelines on the Treatment of Blood Cholesterol to Reduce Atherosclerotic Cardiovascular Risk in Adults [16].

From the results depicted in Table 2, we can ascertain that about $122(71.35 \%)$ were females while $49(28.65 \%)$ were males. Most of the patients above 60 years $78(45.61 \%)$. The majority of the patients have had the condition for less than or 5 years $88(51.46 \%)$ while those who have had the condition for more than 5 years were 83(48.54\%). Only $66(38.60 \%)$ have had their lipids being tested. However,
$105(61.40 \%)$ have not had their lipid tested. Lastly, more of the patients $87(50.88 \%)$ do not use statin while $84(49.12 \%)$ use a statin. while those who have had the condition for more than 5 years were $83(48.54 \%)$. Only $66(38.60 \%)$ have had their lipids being tested. However, $105(61.40 \%)$ have not had their lipid tested. Lastly, more of the patients $87(50.88 \%)$ do not use statin while $84(49.12 \%)$ use a statin. 


\begin{tabular}{|c|c|c|}
\hline VARIABLE & FREQUENCY(n) & PERCENTAGE $(\%)$ \\
\hline \multicolumn{3}{|l|}{ Sex } \\
\hline Male & 49 & 28.65 \\
\hline Female & 122 & 71.35 \\
\hline \multicolumn{3}{|l|}{ AGE } \\
\hline $40-50$ & 35 & 20.47 \\
\hline $51-60$ & 58 & 33.92 \\
\hline Greater than 61 & 78 & 45.61 \\
\hline \multicolumn{3}{|c|}{ DURATION OF DIABETES } \\
\hline Less than 5 years & 88 & 51.46 \\
\hline More than 5 years & 83 & 48.54 \\
\hline \multicolumn{3}{|l|}{ LIPID TEST } \\
\hline No & 105 & 61.40 \\
\hline Yes & 66 & 38.60 \\
\hline \multicolumn{3}{|l|}{ LDL LEVELS } \\
\hline Normal $(\leq 100 \mathrm{mg} / \mathrm{dl})$ & 11 & 16.67 \\
\hline High $(\geq 100 \mathrm{mg} / \mathrm{dl})$ & 55 & 83.33 \\
\hline \multicolumn{3}{|c|}{ GLYCATED HAEMOGLOBIN } \\
\hline Normal $(\leq 7 \%)$ & 19 & 11.11 \\
\hline High $(\geq 7 \%)$ & 152 & 88.89 \\
\hline \multicolumn{3}{|l|}{ STATIN USE } \\
\hline Yes & 87 & 50.88 \\
\hline No & 84 & 49.12 \\
\hline
\end{tabular}

Table 2: socio-demographic characteristics and statin use in type 2 diabetic patients who visited the diabetic clinic

From figure 2 . The majority of patients $(65.45 \%)$ were hypertensive. About $15.45 \%$ had hypertension with peripheral neuropathy whereas only 14.45 of patients had only neuropathy. Lastly, $4.55 \%$ of the patients had other concomitant diseases

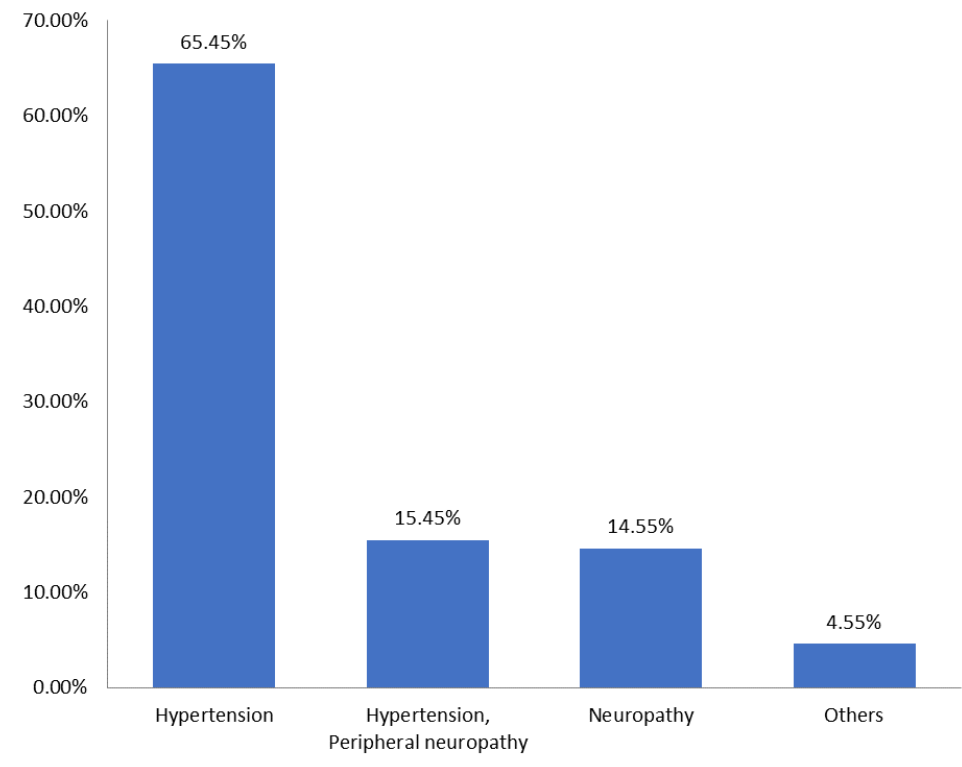

Figure 2: Bar chart showing the distribution of type 2 diabetes and their various type of complications

The results from Figure 3 demonstrates that the most commonly prescribed statin for the primary prevention of cardiovascular disease is Atorvastatin $20 \mathrm{mg}$ which falls into the category of moderate-intensity dosing strategy as shown in Table.1; followed by Atorvastatin $10 \mathrm{mg}$. Atorvastatin $40 \mathrm{mg}$ and Simvastatin $20 \mathrm{mg}$ were the least prescribed statin for primary prevention of cardiovascular disease. 


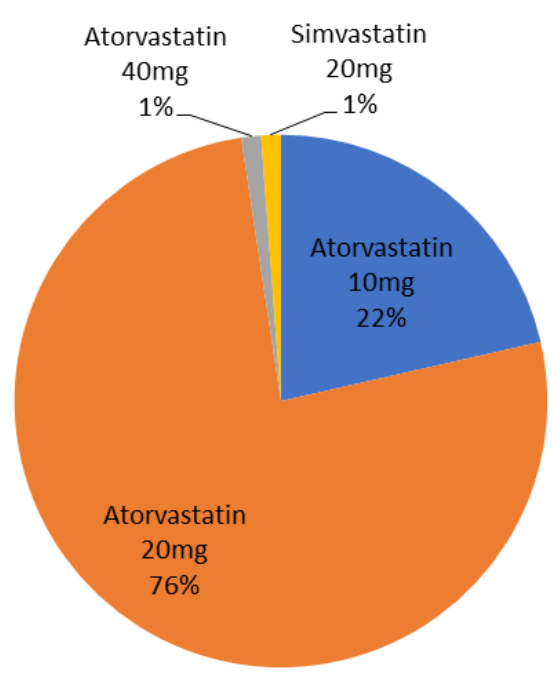

Figure 3: Pie chart showing the distribution of the most commonly prescribed statins for primary prevention of CVD in T2DM Patients

Data from Table. 3 was used to perform a bivariate analysis to test whether there were any possible associations between the socio-demographic factors and statin use. However, none of the socio-demographic variables was associated with statin use since there was none that had a p-value to be less than 0.05 .

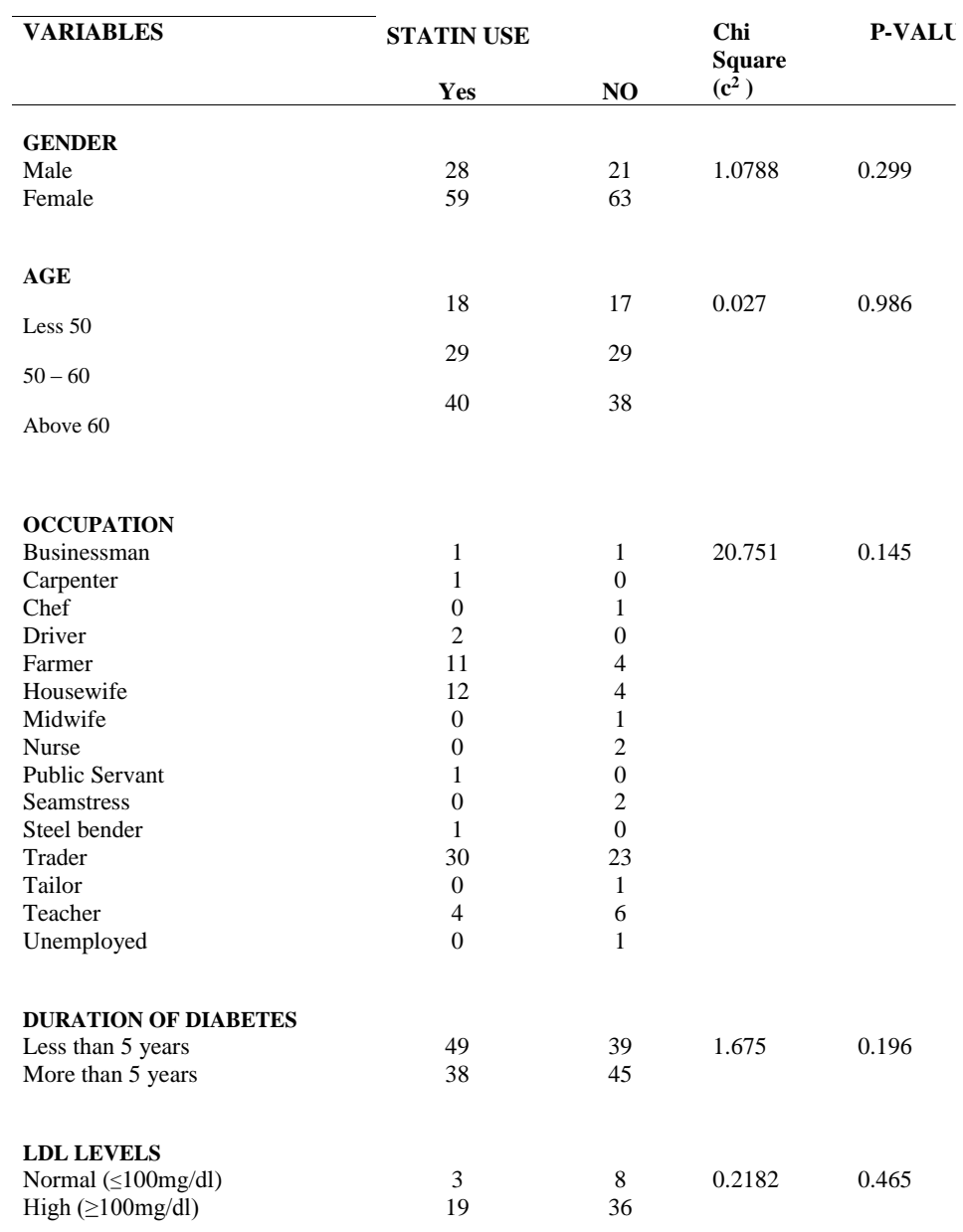

Table 3: Association between the socio-demographic factors and statin use 
From table 4, an analysis was done to test the association between the various conditions and statin use. However, there was no association.

\begin{tabular}{|c|c|c|c|c|}
\hline \multirow[t]{2}{*}{ VARIABLES } & \multicolumn{2}{|c|}{ ON STATIN } & & \multirow[t]{2}{*}{ P-VALUE } \\
\hline & Yes & NO & & \\
\hline Hypercholesterolemia & 0 & 1 & 12.378 & 0.054 \\
\hline Hypertension & 32 & 41 & & \\
\hline Hypertension, Hyperlipidemia & 0 & 2 & & \\
\hline Hypertension, Hyperlipidemia, Peripheral Neuropathy & 0 & 1 & & \\
\hline Hypertension, Peripheral Neuropathy & 7 & 10 & & \\
\hline Peripheral Neuropathy & 13 & 3 & & \\
\hline
\end{tabular}

Table 4: Association between patients with comorbidities and statin use

\section{Discussion}

$\mathrm{n}$ A total of one hundred and seventy-one folders of patients between the ages of 40 to 75 years with T2DM were used in this study with $29 \%$ being male and $71 \%$ being female (Table 3 ). About $46 \%$ of the study population was above 61 years while $20 \%$ were between 40 to 50 years (Table 3 ). It was observed that $51.46 \%$ of patients had been diagnosed with T2DM for more than 5 years while the remaining patients $(48.54 \%)$ had the condition for less than 5 years (Table 2). Some of these patients had other commodities in addition to T2DM with about $65 \%$ having hypertension, $14.5 \%$ having neuropathy and $15.5 \%$ having both hypertension and neuropathy (Table 2). About $89 \%$ of the study population had high recorded glycated hemoglobin (above $7 \%$ ) while approximately $11 \%$ normal recorded glycated hemoglobin $(\leq 7)$ (Table 4/Figure 2). Approximately $49 \%$ of the study population received a statin for primary prevention whilst the other $51 \%$ of the study population were not prescribed a statin (Table 2).

According to the results of the study, about $49 \%$ of respondents who attended the Tamale Teaching Hospital Diabetes Clinic between January to March 2019 were prescribed a statin. These results were considerably higher than other studies conducted in Germany, the United States of America, Denmark and China which reported the percentage of statin

prescription for primary prevention in $\mathrm{T} 2 \mathrm{DM}$ as $33.2 \%, 40 \%, 47 \%$ and $33.8 \%$ respectively [25-28]. In countries such as India, Ethiopia, and Malaysia, the use of statins for primary prevention in T2DM was reported to be $55.2 \%, 55.7 \%$ and $65 \%$ respectively [29.30.31], which are moderately higher than the findings from this study. Against the backdrop of the clearly established benefits of statin for primary prevention among the population in this study, the results purport underutilization of statins among the patient's population who would otherwise benefit from statin use and optimization. The guidelines for medication utilization review in this present study highly recommend statin use among all the participants in this study unless contraindicated [32]. There was no demonstrable or documented contraindication in any of the participants in this study which suggested all the participants should have received a statin.

Among the patients who were prescribed statin therapy, $1 \%$ and $76 \%$ received high intensity and moderate-intensity statin respectively; which is the recommended statin dose for T2DM patients aged 40 years and above with high risk of cardiovascular events [33]. The reason for the underdosing in the other $23 \%$ was not apparently known however, some studies suggest that underutilization of statins for primary prevention in T2DM patients over 40 years may be associated with inappropriate dosing, issues with adherence and discontinuation by patients and argue that some clinicians may decide to go for low dose for safety reasons even when treatment goals are not met [34]: Also, the prescribing of low doses of statins for primary prevention than those recommended by guidelines affect the desired benefits to a patient in the real-world [35]).

Only $39 \%$ (66) patients out of the 171 had their lipid panel performed and quite a significant number of $32 \%$ (55) patients had elevated low density (LDL) lipoprotein levels. Furthermore, only 19 participants out of the 55 had ever been prescribed a statin (Table 3). This is far below the recommendation from clinical practice guidelines for the management of dyslipidemia and primary prevention in the population under this study [36].

From the study conducted, the most commonly prescribed statin in TTH between January TO March 2019 was Atorvastatin 20mg (76\%), Atorvastatin 10mg (22\%), Atorvastatin 40mg (1\%) and Simvastatin 20mg (1\%) (Figure 2). Generally, Atorvastatin constituted about $99 \%$ of all statin therapy prescriptions for primary prevention in T2DM patients who attended the diabetes clinic between January 2019 to March 2019. This is comparable to a study in India where the most commonly prescribed statin for primary prevention in T2DM was Atorvastatin (74.1\%) followed by Rosuvastatin (29.2\%) [37]. Another study in Ethiopia revealed a contrary pattern of simvastatin being the most commonly prescribed statins (37.2\%), followed by Atorvastatin (32.8\%) and Rosuvastatin (15.6\%) [38].

\section{Study Limitations}

The greatest limitation of this study is that the design was not good enough to give the researchers the opportunity to determine the impact of Statin therapy underutilization for primary prevention of CVD in T2DM on the overall cardiovascular morbidity and mortality of these patients. Missing information and information bias from stored records due to differences in manual recording and digital recording. The facility employs both digital and manual patient records keeping. During data collection, it was discovered that the paper-based patient medical records contained more detailed more information than the one on the Health Administration Management System (HAMS) which lead to relying solely on the paper-based medical records for patient-specific data extraction. However, it was highly possible that some prescribers might have imputed some vital patient information on the HAMS but not in the paper-based patient medical record and vice versa. The retrospective nature of the study did not afford the investigators with the opportunity to obtain some relevant answers to questions associated with patient-specific 
information that could have only been answered by the patients whose medical records were selected for this study. More parameters could have been used to ascertain more utilization of statins for primary prevention in totality, however, the allotted time for the research was very limited.

\section{Conclusion}

Despite the overwhelming evidence supporting the cardiovascular benefits of statin therapy for primary prevention of CVD in T2DM patients, these therapeutic agents are under-prescribed for T2DM patients at TTH; with atorvastatin being the most frequently prescribed statin therapy. Clinicians caring for T2DM patients at TTH, generally utilize the moderate-intensity Statin therapy as their preferred dosing strategy for primary prevention of CVD.

\section{Recommendations}

1. Current policies governing the revision and updating of the Standard Treatment Guidelines and National Health Insurance Medicines List and any other guidelines should be revised to include yearly publications of current trends in order to be at par with modern international guidelines.

2. The ministry must recruit and train more Endocrinologists specialized in the clinical management of diabetes. The Ministry of Health in collaboration with the Ghana Health Services should ensure that more of these specialists diabetologists after training are posted to remote areas (Including the TTH) in order to meet the doctor-patient ratio and ensure accessibility of patients with diabetes to quality healthcare.

3. The ministry of health in collaboration with the Ghana health services must liaise with the Ghana Postgraduate of Pharmacists to train and post Specialists Clinical Pharmacists with experts in endocrinology to all Public health facilities. This initiative will ensure that all Patients with T2DM will receive a quality and comprehensive Pharmaceutical Care

4. Implementation of yearly reports of various researches and peer reviews of the application of current guidelines in the primary prevention of CVD as well as comprehensive management of T2DM in clinical practice can be adopted and made accessible for all by the Ministry of Health (MOH).

5. There is a need for more research to be conducted in other hospitals to assess the use of statins for primary prevention among T2DM in those facilities.

6. Regular training, update lectures, and peer reviews for clinicians on current clinical practice guidelines and the evidence-based implementation of these guidelines in realworld clinical practice must be incorporated in current policies for the management of diabetes mellitus.

7. There is a great Need for prescribers to develop and acquire clinical assessment skills to assist them in the implementation of primary prevention management strategies for T2DM patients between $40-75$ years.

8. Need for proper patient education and counseling by all clinicians involved in the management of T2DM patients. This approach will encourage and promote patient adherence to drug therapy and improve therapeutic outcomes

\section{Declaration of the source of funding for this research}

We the researchers do not have any conflict of interest to declare because we have not received any form of financial support from any private or public institutions for the conduct of this research. The activities of this research were conducted using monies from the annual Book and research allowances allocated by the Government of the Republic of Ghana to every researcher within the public research institutions

\section{Declaration of conflicting interests}

No

\section{References}

1. Zeind, CS, Carvalho, MG. Applied therapeutics: The clinical use of drugs. 2018.

2. World Health Organization. Global Report on Diabetes. 2018.

3. DCCT. The effects of intensive treatment of diabetes on the development and progression of long term complications in insulin-dependent diabetes Mellitus. The New England Journal of Medicine. 1993

4. Biadgo, B, Abebe, SM, Baynes, HW, Yussif, M, Alemu, A, Abebe. Correlation between serum lipid profile with anthropometric and clinical variables in patients with type 2 diabetes mellitus. Ethiopian journal of Health Sciences. 2017; 27(3): 215- 226

5. Beckman, J. Diabetes and atherosclerosis: epidemiology, pathophysiology, and Management.

6. Kimando, MW, Otieno, FCF, Ogola, EN, Mutai. Adequacy of control of cardiovascular risk factors in ambulatory patients with type 2 diabetes attending the diabetes outpatient clinic at a county hospital, Kenya 2017. BMC Endocrine Disorders; 17(1): 1-11

7. The ACCORD Study investigators. Intensive blood-glucose and vascular outcomes in patients with type 2 diabetes in 2008 .

8. ADA. Cardiovascular Disease and Risk Management: Standards of Medical Care in Diabetes 2018. 24(1): 9-15

9. Colhoun, HM, Betteridge, DJ, Durrington, Hitman, GA, Neil, HAW, Livingstone, SJ, Thompson. Primary prevention of cardiovascular disease with atorvastatin in type 2 diabetes in the Collaborative Atorvastatin Diabetes Study (CARDS): Multicenter randomized placebo-controlled trial 2004; 23(3): 685-696

10. Wasmann, S, Laufs, U, Baumer, AT, et al. HMG-CoA reductase inhibitors improve endothelial dysfunction in normocholesterolemic hypertension via reduced production of reactive oxygen species. Hypertension 2001; 37: 1450-1457

11. Takemoto M, Node, K, Nakagami, $H$ et al. Statins as antioxidant therapy for preventing cardiac myocyte hypertrophy. J Clin Invest 2001; 108: 1429-1437

12. Blake, GJ, Ridker, PM. Novel clinical markers of vascular wall inflammation. Circ Res 2001; 89: 763-771

13. Joukhadar C, Klein, N, Prinz, M, et al. Similar effects of atorvastatin, simvastatin, and pravastatin on thrombogenic and inflammatory parameters in patients with hypercholesterolemia. Throm Haemost. 2001; 85: 47-51

14. Fredman, DJ, Norrie, J, Sattar, N, et al. Pravastatin and the development of diabetes: evidence for a protective treatment effect in the west of Scotland coronary prevention study. Circulation 2001; 103: 357-362

15. Reboussin, DM, Allen, NB, Griswold, ME, Guallar, E, Hong, Y, Lackland, DT, Vupputuri, S. Systematic Review for the 2017 ACC/AHA Guidelines for the prevention, detection and management of high blood pressure in adults. Circulation 2018; 138(17): 595-616

16. Stone, NJ, Robinson, JG, Lichtenstein, AH, et al. ACC/AHA Prevention Guidelines on the Treatment of blood cholesterol to 
reduce atherosclerotic cardiovascular disease risks in adults. A report of the ACC/AHA Task Force on Practice Guidelines

17. Grundy. SM, Stone, NJ, et al. ACC/AHA Guideline on the management of blood cholesterol. Journal of the American college of cardiology 2019; 73(24): 285-350

18. Wiklund, O, Mattsson-Hulten, I, et al. Effects of simvastatin and atorvastatin on inflammation markers in plasma. $\mathrm{J}$ Inter Med 2002; 251: 338-347

19. Seljeflot, I, Tonstad, S, Hermann, I, et al. Reduced expression of endothelial cell markers after one year of treatment with simvastatin and atorvastatin in patients with coronary heart disease. Atherosclerosis 2002; 162: 179-185

20. Gupta, R, Lodha, S, Sharma, KK, et al. Evaluation of Statin Prescriptions in type 2 diabetes: India Heart Watch-2. BMJ Open Diabetes and Care 2016; 4(1): 101-108

21. Lin, I, Sung, J, Sanchez, RJ, et al. Patterns of Statin Use in the real-word Population of Patients at High Cardiovascular Risk. Journal of Managed Care and Specialty Pharmacy 2016; 22(6): 685-698

22. Grant, AM, Niyonsenga, T, et al. Cardiovascular disease. Physician attitudes toward prevention and treatment. Canadian Family Physician 1998; 44: 780 - 787

23. Ohlson, H, Lindblad, U, et al. Understanding adherence to official Guidelines on statin prescribing in primary health care: A multi-Level methodological approach. Journal of Clinical Pharmacology 2005; 61 (9): 657-665

24. Demoz, GT, Wahdey, S, et al. Prescribing patterns of statins for primary prevention of cardiovascular disease in patients with type 2 diabetes: Insights from Ethiopia. BMJ Research Notes 2019; 12(1): 1-7

25. Berthold, HK, Guouni-Berthold, I, et al. Patterns and predictors of statin prescription in patients with type 2 diabetes. Cardiovascular Diabetology 2009; 8: 861- 867

26. Steen, DL, Khan, I, et al. Patterns and predictors of lipidlowering therapy in patients with atherosclerotic cardiovascular disease and/or diabetes mellitus in 2014: Insights from a large US managed care population. Clinical Cardiology 2017; 40(3): 155-162

27. Mortensen, MB, Kulemovic, I, et al. Statin Use and cardiovascular risk factors in diabetic patients developing a first myocardial infarction. Cardiovascular Diabetology 2016; 15(1): 81-89

28. Collins, R, Armitage, J, et al. The Heart Protection Study of cholesterol-lowering with simvastatin in 20536 high-risk individuals: A randomized placebo-controlled trial. Lancet 2002; 360(9326): 7- 22

29. Gupta, R, Lodha, S, Sharma, KK, et al. Evaluation of Statin Prescriptions in type 2 diabetes: India Heart Watch-2. BMJ Open Diabetes and Care 2016; 4(1): 101-108

30. Demoz, GT, Wahdey, S, et al. Prescribing patterns of statins for primary prevention of cardiovascular disease in patients with type 2 diabetes: Insights from Ethiopia. BMJ Research Notes 2019; 12(1): 1-7

31. Elnamen, MH, Nik, MH. Statin therapy prescribing for patients with type 2 Diabetes Mellitus: A review of current evidence and challenges European society of Cardiology 2013 guidelines on diabetes and cardiovascular disease. Journal of Pharmacy and bioallied Sciences 2013; 6: 78- 89

32. Arnett, DK, Blumenthal, RS, et al. ACC/AHA Guidelines on primary prevention of cardiovascular disease. Journal of the American College of Cardiology 2019; 74 (10): 177-232

33. Grundy, SM, Cleeman, JI, et al. American Heart Association. Implications of recent clinical trials for the National Cholesterol Education Program Adult Treatment Panel III Guidelines. Circulation 2004; 110(2): 227 - 239

34. Lee, VWY, Ho, ICH, et al. Statin utilization patterns for the primary prevention of cardiovascular events: A Retrospective study in patients with diabetes in Hong Kong. Journal of Cardiovascular Drugs 2008; 8(3): 199 - 205

35. Ruokoniemi, P, Sand, R, et al. Are Statin trials in diabetes representative of real-world diabetes care: A population-based study on statin initiators in Finland. BMJ Open 2014; 4(6): 34 $-43$

36. Elnamen, MH, Nik Mohammed, MH, et al. Patterns of Statin therapy prescribing amongst hospitalized patients with type 2 diabetes Mellitus in two Malaysian tertiary hospitals. Tropical Journal of Pharmaceutical research 2017; 16 (12): 3005 - 3011

37. The ASCOT Study Investigators. Reduction in cardiovascular events with atorvastatin in 2532 patients with type 2 diabetes (ASCOT-LLA). Diabetes Care 2005; 28 (5): 1151-1157

38. Berthold, HK, Gouni-Berthold, I, et al. Cardiovascular risk factors in patients with type 2 diabetes in Germany. Deutsches Arzteblatt 2007; 104 (13): 861 - 867

39. Elnamen, MH, Nik, MH. Statin therapy prescribing for patients with type 2 Diabetes Mellitus: A review of current evidence and challenges European society of Cardiology 2013 guidelines on diabetes and cardiovascular disease. Journal of Pharmacy and bioallied Sciences 2013; 6: 78- 89 
(C) (P) This work is licensed under Creative Commons Attribution 4.0 License

To Submit Your Article Click Here: Submit Article

DOI:10.31579/2641-0419/069
Ready to submit your research? Choose Auctores and benefit from:

* fast, convenient online submission

* rigorous peer review by experienced research in your field

* rapid publication on acceptance

* authors retain copyrights

* unique DOI for all articles

* immediate, unrestricted online access

At Auctores, research is always in progress.

Learn more www.auctoresonline.org/journals/clinical-cardiology-andcardiovascular-interventions 